\title{
Basic Requirements for an Innovation Scorecard System
}

This book is a guide to the process for developing, rolling out and the ongoing management of an Innovation Scorecard system that will assist both project and non-project managers to measure how successful innovation has been in their respective work areas.

The authors, who have over 60 years of theoretical and practical work experiences (between them) in areas of change management, suggest that an Innovation Scorecard can be applied across the industries and in any kind of company or organisation. It is important to note that local prevailing cultural differences need to be considered and appropriate adaptations will need to be made to make it fit its intended purpose irrespective of the work environment. The following list presents the fundamental high-level actions that need to be considered and completed before the Innovation Scorecard process can be started:

- Define the scope, including in and out of scope and the measurement background

- Develop a simple Work Breakdown Structure (WBS) to define the work that needs to be undertaken

- Develop stage-gate model

- Set performance objectives (WHAT) and Key Results (HOW)

- Define the measure characteristics

- Define calculations and data specifics

- Produce performance information

- Select innovation metrics

- Create an Innovation Scorecard Data Sheet 